\title{
Liveness: Phelan, Auslander, and After
}

\section{By Daniel Meyer-Dinkgräfe}

Live-cast and recorded theatre (LCRT) such as National Theatre Live has expanded rapidly into a major industry since its launch in 2009. In academic terms, this development has been discussed predominantly in the context of audience demographics. The development merits, however, a reassessment of the liveness debate launched with the seminal contributions by Peggy Phelan’s 1993 book Unmarked: The Politics of Performance and Philip Auslander’s 1999 study Liveness: Performance in a Mediatized Culture. Auslander argues that before mediatization in the forms of sound recording and film, all audiences encountered performance in a mode that we now call "live”. However, that term was not yet relevant then, because it makes sense only in relation to an opposite, such as the "mediatized". ${ }^{1}$ In this sense, the live does not precede the mediatized and cannot claim superiority because it came first. ${ }^{2}$ Once the live emerges as a category of experience, in opposition to the mediatized, those people who are representatives of the live in production or reception contexts develop an anxiety about the perceived threat that the live is allegedly exposed to from the mediatized. ${ }^{3}$ They address that anxiety by attributing higher value to the live by arguing that it is real, whereas the mediatized is not real. ${ }^{4}$ An alternative is the attempt to make the live as alike to the mediatized as possible. ${ }^{5}$ In that case, those who favor the live over the mediatized seek to re-create a mediatized image in a live setting, thus invoking our nostalgia for "what we assumed was the immediate.”" For this response to anxiety, Auslander refers to the helicopter in Miss Saigon as a prominent example. ${ }^{7}$ Another is the suggestion that a live recording is somehow better than a studio recording. ${ }^{8}$

Auslander rejects the arguments developed by of those in favor of the live when they feel threatened by mediatization. The live, he argues, is not first and therefore stronger. The 
claim that the live is real and that the mediatized is unreal, Auslander argues, does not work because the mediatized is just as much a human experience as the live. Auslander also rejects the implication of the higher value of the live recording over the studio recording in terms of the problematic semantics: "This expression is an oxymoron (how can something be both recorded and live?) but is another concept we now accept without question.”9 ${ }^{9}$ an article reflecting on the first edition of Auslander's book, Martin Barker had argued that audiences experience live performance "as if it had elements of uniqueness." 10 This argument was strongly developed by Phelan. ${ }^{11}$ In the $2^{\text {nd }}$ edition of his book, Auslander responds to Barker, suggesting that the audience's hope that a live performance is unique is an illusion. Auslander refers to Barker's qualification that for a live performance of a theatre production to be successful, a performance needs to be such that the "actual variations are probably minimal and insignificant." 12 In the same vein, Auslander Auslander denies that live performance functions to bring performers and spectators into an experience of community. Instead he suggests that the nature of performance is founded on difference, separation, and fragmentation that exclude unity. Auslander refers to the failed attempts by Grotowski and Boal to achieve such desired unity. ${ }^{13}$ He questions the need for a spectator to be present in the same space as the performance to enjoy the experience of watching a performance, ${ }^{14}$ and ultimately concedes only that live performance may afford social prestige to the spectator who can boast to have been present at a live event which carries the value of being memorable by peers. ${ }^{15}$ Live and mediatized, Auslander concludes, are not ontological opposites, but rather cultural and historical contingencies define their opposition. ${ }^{16}$ Despite the fact that Auslander, in his writing about liveness, brought what Barker called a "deep pessimism" ${ }^{17}$ to the debate about liveness, many critics continue the discussion of the nature of liveness. For example, Reason has addressed the concerns about documentation in relation to live performance. ${ }^{18}$ In the context of her argument relating to 
utopian performatives, Jill Dolan writes that, "live performance provides a place for people to come together, embodied and passionate, to share experiences of meaning making and imagination that can describe or capture fleeting intimations of a better world.”19 Bundy et al., and Reason have considered liveness in the context of audience research with younger audiences. Bundy et al. have identified the following:

Characteristics that young people identified as key components of their experience of liveness (...): audience; the comfort and discomfort of presentness; performer vulnerability, risk and uncertainty; proximity to the live action; perceptions of realness; a sense of relationship with the actors; and the intensity of engagement. ${ }^{20}$

Writing about secondary school pupils in the United Kingdom attending a performance of Othello, Reason observed that these spectators experienced the cinema audience as an audience of peers, while they constructed the theatre audience as other people. ${ }^{21}$ With regard to the young spectators' responses to the liveness of the Othello performance, which includes their references to “directness, immediacy, responsibility, realness,” Reason argues that it is necessary to include in the discussion "the wider social phenomenon and experience (...), the public experience of the event.” ${ }^{22}$ He concludes:

the experience of being in a theatre audience is always going to be largely about something very different from simply sitting down and watching a play”. (...) the acuteness of this social experience was heightened by the live nature of the theatre performance - the real presence of the actors, the danger of something going wrong, the risk of missing something all provide an urgency to the situation, increasing levels of tension and potential discord 
within the audience. Like the complex realness of the live actors, so is the theatre audience a heightened, intense and peculiarly real environment. ${ }^{23}$

Paterson and Stevens discuss liveness in the simulcast phenomenon on the basis of NT Live, and propose a “new conceptual framework that can be termed 'Super Bowl Dramaturgy,' whereby the qualities of the 'live' performance are subsumed within a dramaturgical logic that parallels the branding, staging, and viewing experiences of a major mediatized sporting event like the American Super Bowl.” ${ }^{24}$ As part of that discussion, they argue that the advent of the simulcast implies that "live" is being re-defined to include reference to "a live screening where the spectator can view the performance in the same temporal moment that it occurs, though they may be separated by vast spatial distances. ${ }^{25}$ Under the influence of new technologies, the concept of liveness has developed to only refer to temporality (if the event in the theatre and in the cinema happen at the same time, the event in the cinema is also live), at the expense of the once indispensable feature of corporeality. ${ }^{26}$ That redefinition is characteristic of the marketing for the simulcast events — whether the audience really experience those events as live in the same sense as live theatre is a different matter altogether. Conventionally, Paterson and Stevens argue, liveness has been associated with “presence, immediacy, authenticity, community, ephemerality and unpredictability,” and the marketing for NT Live, for example, exploits these in the "nostalgic and affective resonances" of its branding. ${ }^{27}$

Paterson and Stevens point out that the live performance in the theatre that serves as the origin of the simulcast has been created for the purposes of that media transfer, and is not the same performance as other live performances of the same production. Given that the filming on simulcast nights prioritizes the simulcast performances over the live experience of the audience, with cameras obstructing the live spectators' views and actors performing as 
much to camera as to the live spectators, the experience of the live audience is also different from a conventional experience in the theatre.

Auslander further developed his positions in the 1999 and 2008 editions, and in 2012, wrote: "[I]t may be that we are now at a point in history at which liveness can no longer be defined in terms of either the presence of living human beings before each other or physical and temporal relationships.”28

\section{Reassessment 1: Liveness as Physical and Temporal Copresence}

Auslander's position and its later modifications are in need of reassessment given the developments that occurred across a range of relevant fields since they were published. The history of theatre should have demonstrated by now that no matter what the perceived threat to theatre may in any one era, the oft-evoked crisis has so far not led to the its ruin, demise, or disappearance. Throughout history theatre has faced challenges in terms of its institutional contexts and artistic forms. There has always been an attempt to attract new audiences, and research suggests that through the recent development of live simulcasts of theatre performances into cinemas, new, or at least more spectators have been attracted to local theatres. ${ }^{29}$ While the existence of media in relation to theatre does not threaten the very existence of theatre, it does mean that theatre makers must be aware of these developments and respond to them while maintaining the integrity of their art form. That might mean integrating aspects of the media into theatre productions and performances. These integrative approaches are taught at the university level in academic and vocational programs and discussed in a variety of academic contexts.

The integration of media into live performance, however, does not make such a performance less live. It is still the case that in such performances the spectator and the performers are in the same space at the same time-they are “co-present in space,” to invoke 
a concept frequently mentioned in liveness debates. ${ }^{30}$ In the cases of cinema and television, the spectator is not in the same space and time as the performance, and in the case of the simulcast the spectator is not in the same space, but at least almost at the same time- any transmission over distance, analog or digital, comes with a time delay, even if imperceptibly small. It would be futile to try to deny those differences, and moreover, it is unnecessary to remove the unhelpful dimensions of implicit or explicit threats of one medium or art form over another, and the correspondingly implied value judgments. There is sufficient space and a sufficiently large number of potential recipients to render hostile competition obsolete.

\section{Reassessment 2: Subjectivity}

Of particular importance here is the nature of the experience of liveness and how that experience has been expressed. Auslander refers to "the magic of live theatre," the "energy" that supposedly exists between performers and spectators in a live event, and the “community” that live performance is often said to create among performers and spectators." ${ }^{31}$ Live experience in theatre tends to be expressed in terms that make intuitive sense: in addition and close relation to the ones mentioned by Auslander, Dolan, and Bundy. Reason and Barker, for example, identify “immediacy, intimacy, buzz, learning, and being (in) the audience." 32 These are very subjective experiences, and the concepts employed to capture them have been intuitive, metaphorical, and subjective: Watson's description of theatre artist Eugenio Barba’s writings apply here as well:

Barba is essentially a creative artist, a poet both in the theatre and in his writings about it. This poetic quality calls for a careful reading of his ideas since he favors poetic metaphors over the more traditional intellectual approach of deductive logic to sustain his arguments. ${ }^{33}$ 
Auslander is explicitly skeptical about such experiences, which he considers to be “traditional, unreflective assumptions” that invoke "clichés and mystifications.”34

The subjective nature of the experience of liveness in the theatre, and consequently, the way such experiences are reported, has led to concerns about that subjectivity. That concern is closely related to a predominantly positivist, materialistic, and scientific worldview, for which the subjective is suspicious by definition. The methods and concepts of science have been unable to capture the subjective, and have therefore ruled it out in favor of objectivity. Nonetheless, in recent years science has begun to incorporate subjectivity in the form of first person approaches to consciousness, especially in the context of consciousness studies. ${ }^{35} \mathrm{~A}$ number of new research methods have evolved to emphasize the value of alternative, participatory modes of knowing, e.g., Intuitive Inquiry, Organic Research, and Heuristic Inquiry. ${ }^{36}$ Within these approaches, “[R]eality is contacted through physical sense data, but also ... through a deep intuitive inner knowing. Awareness includes (objective) sensation as well as (subjective) intuitive, aesthetic, spiritual, [and] noetic . . . aspects. Understanding comes ... from identifying with the observed, becoming one with it,” and the “entire spectra of states of consciousness are of interest. . . ”37 This is a notion echoed by Tart, who advocated the development of state-specific sciences, suggesting that nonordinary states of consciousness are likely to yield new insights not accessible by conventional methods. $^{38}$

Part of this turn towards first person approaches in consciousness studies, probably very closely related to the performative turn in the arts as well as in the humanities and social sciences, is the consideration of traditional wisdom forming the heritage of different cultures as potentially fruitful in innovatively and rigorously addressing pressing issues. The model of consciousness proposed by Indian Vedanta philosophy is one such example. It has been used 
in different contexts to help explain phenomena of literature and theatre in more consistent ways than other models. ${ }^{39}$ This model is applicable to the liveness debate, and it can therein develop a better understanding of the subjective experiences reported in relation to it. It does so without becoming redundant and without destroying any poetic aspect of current reports of that experience.

According to the model proposed by Vedanta philosophy, consciousness comprises three conventionally experienced states: waking, dreaming, and sleeping. At their basis is pure consciousness or turiya. Malekin and Yarrow describe it as follows:

Turiya is an underlying unconditioned consciousness, which appears limited when reflected through the three contingent states of the individual mind. In itself it is a self-effulgent radiance akin to the intelligible sun of St Simeon and the irradiation from the One of Plotinus. It is, in the deepest sense, the reality of the mind and, according to Gaudapada and Shankara, Reality itself. ${ }^{40}$

When waking, dreaming, or sleep coexist with pure consciousness, thus defined, a "higher" state of consciousness has been achieved — the ultimate aim of human spiritual development. “Higher” means “more comprehensive and more integrated." 41

In terms of the consciousness studies debate, the Vedanta model offers a solution to the hard problem invoked by Tom Stoppard's new play with the same title. ${ }^{42}$ David Chalmers argued that the hard problem of consciousness is how to explain why and how certain physical processes give rise to a rich inner life. ${ }^{43}$ If adopting the Vedanta model of consciousness, the causal relationship in need of explanation is the reverse. The Vedanta approach argues that physical processes are a concretization—or manifestation—of consciousness, and provide information as to why and how consciousness proceeds to manifestation. ${ }^{44}$ The hard problem is thus solved, first and foremost, on the level its 
formulation set out to discover in the first place: experience. The Vedanta model fulfills Chalmers' demands to take consciousness as a fundamental entity in nature; it even goes beyond Chalmers in proposing consciousness as the ultimate fundamental entity, the very basis of fundamental entities in physics, like space and time, for example. The latter are set as fundamentals because physicists cannot, at present, explain their existence any further. Such relative fundamentals are thus an intellectual construct. Consciousness as the basis of all creation as proposed by Vedanta is no such intellectual construct: instead, it is the linguistic/verbal rendering of the deepest experience possible to the human mind. Why was the hard problem taken to be so hard that some authors, such as McGinn, claim it can never be solved? McGinn is perfectly right to state: "it is quite predictable that our intellects should falter when trying to make sense of the place of consciousness in the natural order.” ${ }^{\text {" }}$ The intellect on its own, isolated from the basis in pure consciousness, can by definition not grasp levels of reality that are originating from a subtler level. Intellect informed by pure consciousness, however, is able to fathom the very depths of consciousness, thereby enabling intellectual understanding of experiences encountered at subtle levels.

In the context of the liveness debate, the Vedanta model (is able to) provides an enhanced understanding of the concepts that Auslander and others have considered with skepticism, the aspects that make liveness so attractive to audiences. Pure consciousness, (according to the Vedanta model,) is omnipresent: it is the basis of everything in the universe, and humans can directly experience it in or through their own minds. The physiology of the brain is the complex tool that permits that experience. Through their creations at all levels, humans can also directly give expression to pure consciousness if a dramatist creates a play or an actor creates a character. This act of creation implies imbuing the created work with pure consciousness. That human creation, the play or the performance of the character, will partake in, consist of, or reflect pure consciousness to the extent that it has been put in by the 
dramatist or the actor, depending on the level of consciousness they have been able to achieve in their respective lives. The recipient, reader, or spectator can in turn experience pure consciousness to the extent that they have developed their own consciousness relative to viewing a performance. Development of consciousness is here to be understood as the extent to which those individuals have integrated pure consciousness with waking or dreaming or sleeping. The higher a person's level of consciousness, the more pure consciousness they can bring to that which they experience, and consequently, the more they can perceive and access pure consciousness in the world around them. They will then refer to experiences of pure consciousness, which are within the range of every human being, culturally different in terms of the? language and concepts at their disposal. In the Chinese context, those experiencing pure consciousness might refer to it in terms of the subtle energy form of chi, in contexts of Vedanta, prana. In Western cultural history, Paracelsus wrote about “archaeus,” Newton about “cosmic aether,” Mesmer about "universal fluid,” and Sheldrake about "morphogenetic fields"- this list is by no means complete. ${ }^{46}$ I propose that these phenomena are exchanged between performers and spectators during a performance: in Vedanta terms, pure consciousness. When we are in the waking state, we experience consciousness in terms of contents: we perceive through the senses, and we think, for example. Pure consciousness on its own is experienced as devoid of such contents: hence, pure. All that exists in that state of consciousness is pure bliss. When pure consciousness coexists with other states of consciousness, the experience of bliss remains. Consequently, the more pure consciousness the actors are able to integrate into their acting, and the more the spectators can experience it, the more enjoyable the experience will be for both. The art form of theatre has particular potential for allowing those involved in it-actors and spectators- to reach intensive experiences of pure consciousness, more intensive than in other areas of life. What is in fact 
an experience of pure consciousness is conceptualized in lay terms as "energy" that spectators can "feel" to exist in the theatre.

If we thus understand better what happens in terms of energy in the theatre, such better understanding cannot diminish our experience of it. On this basis we can go even further in our attempt of understanding. In the context of meditation practices, empirical science has researched psychophysiological correlates of pure consciousness. ${ }^{47}$ It should therefore be possible to design further empirical research to explore the hypothesis that actors and audiences will express a stronger experience of energy, or the "magic of theatre," in direct correlation to the extent to which actors and audiences experience pure consciousness. These studies would likewise include refined breathing (suspension of breathing between 1040 seconds during the experience of pure consciousness), related skin conductance responses at the onset of changes of the breathing pattern, and measurements of the brain activity through EEG readings. I have offered suggestions for an enhanced understanding of the reasons why live performance may be perceived as different from a performance that is not live, and why the experience of liveness is often associated in audience reports with references to intangible aspects such as energy. These suggestions offer opportunities for readers to bring their wide spectrum of interests and areas of expertise to the debate (all the contexts for subtle energy, consciousness studies, and qualitative and quantitative empirical approaches). These suggestions also open up opportunities for cross-disciplinary communication: the findings in different areas about the same phenomenon need not be (considered as) mutually exclusive! In the same vein, with repeated emphasis that the nature of the live experience of performance, thus better understood, does not imply a value judgment, further research can investigate the specific characteristics of the experience of film and television that make it different from (not inferior than) live performance. If the physical presence of the performer allows the direct exchange of energy between performers 
and spectators, different mechanisms must be at work in creating the impact of film and television on the spectator, and the impact of the creative process on film and TV actors is also likely to be different as they are not in the presence of their spectators. In physiological terms, for example, it should be possible to hypothesize, and subsequently put to the test, that live actors will provide the brain with 3D stereo cues that are not present in conventional 2D screen viewing. Further thought and subsequent empirical research could address the question of whether the same or different brain areas are active in response to true $3 \mathrm{D}$, and screen $3 \mathrm{D}$ (given that the projection of $3 \mathrm{D}$ is onto a flat screen), or whether the same brain areas respond to these different cues in subtly different ways. ${ }^{48}$ Or are the differences between true 3D, screen 3D, and 2D more to do with subtle "liveness" perception or immersion than with the visual cues themselves? ${ }^{49}$

\section{Reassessment 3: Simulcasts}

Thus far I have established the difference between live and nonlive, and have suggested ways for explaining the attraction of the live in relation to experiences exclusive to it in terms of the direct exchange of pure consciousness between actors and spectators. The simulcast happens almost at the same time, but spectators and actors are not in the same physical space. There is anecdotal evidence, supported by a number of empirical studies, that people can influence other people independent of physical copresence. Here is an example in the context of theatre:

American director Peter Sellars made an experiment: actors in one of his productions were on stage and played a scene, as rehearsed, which contained by nature a number of specific emotions. Neither those on-stage actors, nor the audience knew that backstage, a further group of actors were doing a range of 
exercises intended to allow them to engage deeply with specific emotions. Sellars's idea was that these backstage actors would be radiating emotions. The emotions he instructed them to engage in were either exactly the same emotions portrayed by the actors onstage, or exactly the opposite ones. Both onstage actors and spectators noticed a difference in atmosphere. Actors commented on most successful performances with a special ease of portraying emotions when the backstage group had enforced their emotions, and of a tough and frustrating performance with difficulties of getting into their emotions when the backstage actors had engaged in emotions opposed to theirs. $^{50}$

The findings of this experiment make sense when considered in relationship to the Vedanta model: consciousness is a field that is omnipresent. This position may well have unexpected impact on the liveness debate. If consciousness is indeed omnipresent, spectators in the cinema watching a live-cast should, through the very nature of the event, become part of the field of consciousness created in the theatre; the reverse functions similarly, given that experiencing the performance in the theatre and in the cinema for the duration of the performance and its simulcast is one subfield of consciousness in the overall field of consciousness. This does not apply to the reception process for film and television, because there is no live event—past or present — that could constitute a subfield of consciousness outside the cinema or the viewing experience of TV typically in the living room. The film or TV broadcast will have its subfield of consciousness specific to its history and processes of creation. Thus the viewer's consciousness will be influenced by both the contents of what they watch on the screen, and by the subfield of consciousness that emerges from the history and 
processes of creation. The liveness of the actors and production team that created that subfield of consciousness is a minor part of the components that make up that subfield. The liveness of the actors on the stage from which the production is simulcast into the cinema is comparatively a much stronger contributor to the subfield of consciousness, and therefore, its impact on the viewer's experience must be assumed to be stronger.

\section{Conclusion}

There are clear and undeniable differences between live performance, simulcast, cinema screening, and TV broadcast in terms of creation and reception. These differences do not imply value judgments, and the different art forms or media do not represent threats to each other. Consciousness studies, especially the Vedanta model of consciousness, facilitates an enhanced understanding of experiences reported by spectators in relation to liveness, thereby enabling an appropriately refreshing context for understanding the new phenomenon of simulcast. This understanding of liveness for the theatre and simulcast opens up many opportunities for further cross-disciplinary dialogue and research. 


\section{Notes}

1. Philip Auslander, Liveness: Performance in a Mediatized Culture, 2nd edition (London: Routledge, 2008) 56.

2. 11 .

3. 7.

4. 3.

5. 6.

6. 43.

7. 26.

8. 60 .

9. 60 .

10. Martin Barker, “Crash, theatre audiences, and the idea of 'liveness,'” Studies in Theatre and Performance 23.1 (2003): 28.

11. Peggy Phelan, Unmarked: The Politics of Performance (London: Routledge, 1993).

12. Auslander, Liveness, 64.

13. 65.

14. 69.

15. 66 .

16. 11 .

17. Martin Barker, Live at Your Local Cinema: The Remarkable Rise of Livecasting (Basingstoke: PalgravePivot, 2013) 43.

18. Matthew Reason, Documentation, Disappearance and the Representation of Live Performance (Basingstoke: Palgrave Macmillan, 2006).

19. Jill Dolan, Utopia in Performance: Finding Hope at the Theatre (Ann Arbor: University of Michigan Press, 2005) 2. 
20. Penny Bundy, Kate Donelan, Robyn Ewing, Josephine Fleming, Madonna Stinson, and Meg Upton, “Talking about Liveness: Responses of Young People in the Theatrespace Project,” NJ: DramaAustralia Journal 36 (2012): 18.

21. Matthew Reason, "Young audiences and live theatre, Part 2: Perceptions of liveness in performance,” Studies in Theatre and Performance 26.3 (2006): 223.

22. 239.

23. 240.

24. Eddie Paterson and Lara Stevens, "From Shakespeare to the Super Bowl: Theatre and Global Liveness,” Australasian Drama Studies 62 (2013): 147.

25. 155.

26. 155, with reference to Steve Dixon, Digital Performance (Cambridge, Mass.: MIT Press, 2007) 127.

27. 156.

28. Philip Auslander, “Digital Liveness: A Historico-Philosophical Perspective,” PAJ: A Journal of Performance and Art 34.3 (2012): 6.

29. Hasan Bakhshi and David Throsby, "Digital complements or substitutes? A quasi-field experiment from the Royal National Theatre,” Journal of Cultural Economics 38 (2014): 1-8. 30. Barker, Local Cinema, 43.

31. Auslander, Liveness, 2.

32. Barker, Local Cinema, 65.

33. Ian Watson, Towards a Third Theatre: Eugenio Barba and the Odin Teatret (London and New York, Routledge, 1993) 18.

34. Auslander, Liveness, 2.

35. Francisco J. Varela and Jonathan Shear, "First-person methodologies: What, why, how,” Journal of Consciousness Studies 6.2-3 (1999): 1-14. 
36. Rosemary Anderson, “Intuitive inquiry: A transpersonal approach,” Transpersonal research methods for the social sciences: Honoring human experience, eds. William Braud and Rosemary Anderson (Thousand Oaks, CA: Sage Publications, 1998) 69-94. Jennifer Clements, "Organic inquiry: toward research in partnership with spirit,” Journal of Transpersonal Psychology 36.1 (2004): 26-49. Clark Moustakas, Heuristic Research: Design, Methodology and Applications (London: Sage, 1990).

37. 10-11.

38. Charles T. Tart, "States of consciousness and state- specific sciences," Science 176 (1972): $1203-1210$.

39. See Peter Malekin and Ralph Yarrow, Consciousness, Literature and Theatre: Theory and Beyond (Basingstoke: MacMillan, 1997). For a survey of publications on consciousness studies in relation to literature, theatre ,and the arts since 2000, many of which use the Vedanta model of consciousness, see Daniel Meyer-Dinkgräfe, Theatre, Opera and Consciousness: History and Current Debates (Amsterdam: Rodopi, 2013).

40. Malekin and Yarrow, Consciousness, Literature and Theatre, 38.

41. 39.

42. Tom Stoppard, The Hard Problem (London: Faber\&Faber, 2015).

43. David Chalmers, The Conscious Mind: In Search of a Fundamental Theory (Oxford: Oxford UP, 1996).

44. Daniel Meyer-Dinkgräfe, Theatre and Consciousness: Explanatory Scope and Future Potential (Bristol: Intellect, 2005) Appendix 2, pages 217-222.

45. Colin McGinn, “Consciousness and Space,” Explaining Consciousness: The Hard Problem, ed. Jonathan Shear (Cambridge, Mass: MIT Press) 105, emphasis added. . 46. Paul J. Rosch, "Bioelectromagnetic and Subtle Energy Medicine: The Interface between Mind and Matter,” Annals of the New York Academy of Science 1172 (2009): 297. 
47. See Frederick Travis and Craig Pearson, "Pure Consciousness: Distinct Phenomenological and Physiological Correlates of 'Consciousness Itself,'” International Journal of Neuroscience 100.1-4 (2000): 77-89.

48. For a recent survey of research into the human visual system in the context of 3D vision, see Martin S Banks, Jenny C.A. Read, Robert S. Allinson, and Simon J. Watt, “Stereoscopy and the Human Visual System,” SMPTE Motion Imaging Journal 121.4 (2012): 24-43. 49. John G Apostolopoulos, Philip A Chou, Bruce Culbertson, Ton Kalker, Mitchell D Trott, and Susie Wee, “The Road to Immersive Communication,” Proceedings of the IEEE 100.4 (2012): 974-990. I am grateful to George Mather, Professor of Psychology, University of Lincoln, for this and the previous reference.

50. Daniel Meyer-Dinkgräfe, "Cold Dark Soft Matter Research and Atmosphere in the Theatre,” Body Space Technology 6 (2006): n.pag. Web. 31 January 2015. <http://people.brunel.ac.uk/bst/vol0601/home.html> 